\title{
TECNOLOGIAS DE GESTÃO, COLABORAÇÃO E COMUNICAÇÃO NO APOIO AO ENSINO DO PROCESSO PROJETUAL PARA CONSTRUÇÃO DE MODELOS MULTIESCALAS INTEGRADOS ${ }^{1}$
}

\author{
MANAGEMENT, COLLABORATION AND COMMUNICATION TECHNOLOGIES \\ IN TEACHING SUPPORTING TO THE PROJECTUAL PROCESS FOR \\ BUILDING INTEGRATED MULTISCALES MODELS
}

\author{
Patrícia Porto Carreiro \\ Universidade Federal de Pernambuco, UFPE \\ ppc@ufpe.br \\ Rejane de Moraes Rêgo \\ Universidade Federal de Pernambuco, UFPE \\ rejane.rego@ufpe.br \\ Adeilton Feitosa \\ adeilton.feitosa.1@gmail.com \\ Maria Augusta Holanda \\ mariaaugustarodriguesdeholanda@gmail.com \\ Maria Carollina Balbino \\ carolfeitosabalbino@gmail.com \\ Mirella Almeida Marins \\ mirellaalmeidamm@gmail.com
}

\begin{abstract}
Resumo
A experiência didático-pedagógica relatada nesse artigo foi realizada na disciplina Informática aplicada à Arquitetura, Urbanismo e Paisagismo I (InfoAU-I) do Curso de Arquitetura e Urbanismo da Universidade Federal de Pernambuco (CAU/UFPE). Defende-se um novo perfil de atuação profissional para arquitetos-urbanistas como gestor de processos projetuais, tendo consequências diretas no ensino da área, pela necessidade do desenvolvimento de habilidades e competências vinculadas ao uso consciente de recursos das tecnologias de Gestão, Comunicação e Colaboração de Informações. Nesse contexto, a disciplina tem por objetivo a construção colaborativa de modelos multiescalas integrados com ênfase em mapas temáticos georreferenciados e modelos geométricos 3D. Define-se modelos muitiescalas integrados como sendo aqueles que, independente da sua plataforma computacional, possibilitam a compreensão e projetação de soluções espaciais integradas, respaldando o princípio da indissociabilidade do ato projetual do edifício, da paisagem e da cidade, preconizado pelo Projeto Pedagógico de Curso do CAU/UFPE. Desenvolvida sob princípios da pesquisa-ação, a experiência
\end{abstract}

1 PORTO CARREIRO, P.; RÊGO, R. M.; FEITOSA, A.; HOLANDA, M. A.; BALBINO, M. C.; MARINS, M. A. Tecnologias de gestão, colaboração e comunicação no apoio ao ensino do processo projetual para construção de modelos multiescalas integrados. In: ENCONTRO BRASILEIRO DE TECNOLOGIA DE INFORMAÇÃO E COMUNICAÇÃO NA CONSTRUÇÃO, 7., 2015, Recife. Anais... Porto Alegre: ANTAC, 2015. 
registra por parte dos alunos maior compreensão dos requisitos conceituais e instrumentais necessários para uma atuação projetual integrada, como também, maior consciência de próprio processo de projetação e da necessidade de aporte metodológico e gerencial para tal. Conclui-se apresentando dificuldades encontradas e melhorias futuras que serão implantadas na disciplina.

Palavras-chave: Gestão da informação. Comunicação. Colaboração. Projetação. Ensino.

\begin{abstract}
This article reports the didatic and pedagogical experience that took place in the course discipline "Informatics applied to Architecture, Urbanism and Landscape I (InfoAU-I)", of the Architecture and Urbanism undergraduation course of the Federal University of Pernambuco (CAU/UFPE). It is defended a new profile of professional practice for architects / planners as projective processes manager, having direct consequences in the teaching of the area needs to develop skills and competencies linked to the conscious use of Management, Communication and Collaboration Information technology resources. In this context, the course aims to the collaborative construction of integrated multiscale models with an emphasis on geo-referenced thematic maps and geometric 3D models. It is defined integrated muitiscale models as those which, regardless of their computing platform, enable understanding and of projecting integrated spatial solutions, supporting the principle of indivisibility of projetual act of building, landscaping and town-planning, recommended by the Pedagogical Course Project the CAU/UFPE. Developed under of action-research methodological principles, the experience remark the students better understanding of the conceptual and instrumental requirements for an integrated architectural design performance, but also a greater awareness of the process of designing and the need for methodological and managerial contribution to such. The conclusion presents the difficulties encountered and future enhancements that will be implemented in the course.
\end{abstract}

Keywords: Information management. Communication. Collaboration. Designing. Teaching.

\title{
1 INTRODUÇÃO: ENFRENTANDO DESAFIOS PEDAGÓGICOS E PROCESSUAIS
}

Porto Carreiro; Rêgo (2013, p. 590) alegam que "muitas vezes, pela falta de um suporte conceitual, o ensino do Projeto se limita a uma repetição irreflexiva da prática pedagógica em detrimento da reflexão consciente sobre os problemas reais, o ofício e o próprio processo projetual".

Com este horizonte investigativo, percebe-se, globalmente, que há mais de 30 anos, se vem gerando dados digitais sobre cidades em vários tipos de sistemas de informação computacionais, tais como: Computer Aided Design (CAD), Building Information Modeling (BIM), Geographic Information System (GIS) ou sistemas aplicados que urgem serem integrados. E, localmente, o contexto da implantação do novo Projeto Pedagógico de Curso (PPC2010) do Curso de Arquitetura e Urbanismo (CAU) da Universidade Federal de Pernambuco (UFPE) explicita o quão complexo é a gestão (da informação) do próprio processo projetual. Fica evidente a necessidade, não só do apoio conceitual como acima mencionado, mas também, instrumental, metodológico e gerencial para sua efetiva realização no ensino e na prática profissional. O PPC2010 ainda defende um novo perfil de atuação profissional para arquitetos-urbanistas como gestor de processos projetuais, tendo consequências diretas no ensino da área, pela necessidade do desenvolvimento de habilidades e competências vinculadas ao uso consciente de recursos das tecnologias de Gestão, Comunicação e Colaboração de Informações.

Toma-se, assim, por premissas os desafios (a) pedagógicos concernentes com a implantação do PPC2010 (AMORIM et al., 2014) e (b) da gestão do processo projetual que também está relacionado diretamente à construção e à manipulação de dados digitais em diversos modelos computacionais de representação de cidades, de paisagens e de edifícios.

Neste artigo, define-se modelos muitiescalas integrados como sendo aqueles que, independente da sua plataforma computacional, possibilitam a compreensão e projetação de soluções espaciais integradas, respaldando o princípio da indissociabilidade do ato projetual nas três escalas espaciais - do edifício, da paisagem e da cidade -, preconizado pelo PPC2010 (PORTO CARREIRO; RÊGO, 2014). 
Neste contexto, o artigo tem por objetivo apresentar procedimentos construídos pelo grupo de InfoAU e testados na experiência didática em andamento da disciplina Informática aplicada à Arquitetura e Urbanismo I (InfoAU-I), do primeiro período do CAU/UFPE. Tais procedimentos focam a construção colaborativa de modelos multiescalas integrados, com ênfase em mapas temáticos georreferenciados e modelos geométricos 3D para representação e análises básicas de áreas urbanas em estudo na disciplina de Projeto de Arquitetura, Urbanismo e Paisagismo I (Projeto I).

A experiência de ensino adota procedimentos metodológicos da pesquisa-ação (THIOLLENT, 1994) e nos últimos três semestres letivos tem-se utilizado a exploração de ferramenta online, de fácil aprendizado e domínio (Google Maps, SketchUp e Google Earth) de modo a privilegiar a construção do processo de colaboração na elaboração e integração de mapas georreferenciados e de modelos geométricos tridimensionais.

Por conta de a carga horária da disciplina ter apenas 30h/a, na construção colaborativa de modelos geométricos 3D é adotado um exercício-piloto (descrito no item 3.1), adequado tanto à compreensão de princípios fundamentais da modelagem geométrica 3D como ao trabalho colaborativo. A cada etapa do processo são discutidas quais questões de gestão e de comunicação de informações são pertinentes, as atribuições de cada estudante dentro de sua equipe e as exigências para que as modelagens parciais resultem numa modelagem geral exitosa. Uma vez compreendido o processo no exercício-piloto, considera-se que os estudantes estarão aptos a replicá-lo na modelagem da área de estudo do período e outras ocasiões similares dentro do curso.

Os resultados parciais indicam que a experiência tem sido satisfatória, em se tratando de estudantes calouros, que passam a trabalhar com a indissociabilidade do ato projetual em modelos multiescalas integrados.

A seguir, detalha-se a experiência realizada no período do semestre 2012.2 ao 2014.2, à qual foi sendo melhorada a partir da avaliação do processo e de seus resultados, com base em procedimentos metodológicos de pesquisa-ação (THIOLLENT, 1994).

\section{USO DAS TECNOLOGIAS DE GESTÃO, COLABORAÇÃO E COMUNICAÇÃO DE INFORMAÇÕES: FORMANDO GESTORES DE PROCESSOS PROJETUAIS}

Do ponto de vista profissional, o PPC2010 possibilita integrar a vivência da cidade à educação formal do arquiteto-urbanista, por meio de uma formação voltada a uma realidade socioambiental, concretizada por exercícios projetuais pautados nas necessidades de comunidades locais, buscando-se melhorar a forma de viver dos indivíduos e, por consequência, a intervenção sociocultural do arquiteto-urbanista na contemporaneidade. Assim, além de reforçar a importância do trabalho desse profissional, incrementa um novo perfil, como gestor de processos projetuais, e não só como coordenador dos vários profissionais envolvidos na execução de um projeto arquitetônico, mas priorizando a gestão do próprio processo projetual.

Em InfoAU-I, intenciona-se inserir o estudante calouro no contexto da projetação em ambiente computacional, explorando procedimentos que são inerentes ao emprego de Tecnologias de Gestão, Colaboração e Comunicação de Informação. Defende-se que um gestor de processo projetual deve desenvolver várias habilidades e competências, não só ligadas ao processo projetual em si - suas etapas e os recursos conceituais e instrumentais necessários a cada uma delas - mas, também, à gestão do processo projetual. Especificamente, na gestão, comunicação e colaboração das informações geradas neste processo, por se considerar a 
projetação como um processo de gestão da informação².

Contudo, atualmente, na academia e no mercado, é perceptível um modismo de rótulos para definir termos ligados a informação. Acredita-se que isto ocorra porque a informação perpassa por vários campos do saber, dificultando se ter definições aceitas por todos eles, mas também, porque define campos de atuação, delimitando espaços, funções e tipos de atividades nas estruturas socioeconômicas. Neste sentido, para melhor se justificar o perfil profissional de gestor de processos projetuais para o arquiteto-urbanista, antes se faz necessário apresentar o contexto atual do mundo globalizado e as competências essenciais necessárias a toda atividade profissional dentro deste contexto.

\subsection{Revoluções tecnológicas e riquezas: entendendo o contexto mundial}

Em 1968, Ribeiro (2001) foi pioneiro quando propôs um enquadramento cultural da história da humanidade. Após identificar e estudar oito revoluções tecnológicas que marcaram e redirecionaram o desenvolvimento humano - a Agrícola, a Urbana, a do Regadio, a Metalúrgica, a Pastoril, a Mercantil, a Industrial e a Termonuclear, esta última do pós Segunda Guerra Mundial -, defendeu que os avanços civilizacionais não ocorriam por conta das lutas de classe, mas sim por meio destas revoluções. Consubstanciado na antropologia, mostrou que cada revolução tecnológica promoveu avanços civilizatórios e transformações irreversíveis nas formas do relacionamento humano e, por consequência, sobre os contextos socioculturais em que ocorreram, gerando novas formações culturais.

$\mathrm{Na}$ década de 80, quando o microprocessador e a internet se difundiram, ratificaram a teoria sobre as etapas de evolução da humanidade de Ribeiro (2001) que antecipou e justificou as grandes transformações e as atuais formas humanas de viver e conviver que acompanhamos nestes últimos 30 anos.

Relacionadas a estas revoluções tecnológicas, ao longo da história, cultuamos vários tipos de riquezas: mercearias como o sal e o açúcar, minérios como o ouro e a prata, a força de trabalho em oficinas de artesãos ou em indústrias e, desde meados do século passado, com os adventos do microprocessador, da Internet estendendo-se até os atuais dispositivos eletrônicos móveis, cultuamos a informação. Nestas primeiras décadas do século XXI, a informação vem ganhando um valor agregado: é georreferenciada. Ou seja, a localização geográfica ${ }^{3}$ hoje vem redefinindo conceitos, dinâmicas e as relações entre estes.

Contudo, já no final do século XX, Castells (1999) definiu bem o nosso contexto atual:

Novas tecnologias de informação integraram o mundo em rede. $A$ comunicação mediada por computadores gerou e continua a gerar uma gama enorme de comunidades virtuais. Transformou-se o nosso modo de pensar, de produzir, de consumir, de negociar, de administrar, de comunicar, de viver, de morrer e até de fazer amor. Surgiram novas formas de um capitalismo mais ágil, mais flexível, com grande capacidade de se adaptar às novas realidades. $\mathrm{E}$ as redes passaram a ter importância decisiva na organização da atividade humana, em todos os domínios da vida social e econômica.

A curto prazo, a informação tornou-se tão importante que, economicamente, trocou-se o

2 Uma discussão mais detalhada pode ser encontrada em: RÊGO, R. M.; PORTO CARREIRO, P. Fundamentos da Gestão de Informação Projetual em Curso de Arquitetura e Urbanismo. In: ENCONTRO BRASILEIRO DE TECNOLOGIA DE INFORMAÇÃO E COMUNICAÇÃO NA CONSTRUÇÃO, 7., 2015, Recife. Anais... Porto Alegre: ANTAC, 2015. p. 1-7.

3 Neste artigo, a localização geográfica é entendida com um ponto que pode ser identificado no mapa mundi por uma coordenada cartesiana (X,Y,Z) e registrada por um GPS (Global Positioning System) em termos da latitude, altitude, longitude. 
binômio capital-trabalho para o informação-conhecimento ${ }^{4}$ como fatores determinantes para qualquer atividade profissional. A informação e o conhecimento são a chave da produtividade e da competitividade. Qualquer processo projetual atual exige gestão consciente da informação para tomadas de decisão coerentes e eficazes.

Castells (1999) ainda chamou atenção para que a maior transformação atual está nas ideias e nas concepções, pois passa-se do material para o imaterial em termos de: (a) poder, embora real, tornou-se imaterial, pois toma como riquesa a informação; (b) o espaço dos fluxos passou a dominar o espaço dos lugares e (c) o tempo imaterial passou a substituir o tempo cronológico. Estas mudanças no Poder, Tempo e Lugar explicam boa parte das complicações criadas pela revolução tecnológica gerada pelos dispositivos digitais (computadores, redes computacionais e dispositivo móveis) em nossas vidas e que provovem novas competências necessárias a qualquer atividade profissional.

\subsection{Novas habilidades e competências essenciais às atividades profissionais}

No atual contexto, Castells (1999) expôem três verdades e propõe duas competências essenciais a qualquer atuação profissional. As verdades são:

COMUNICAÇÃO - A primeira verdade é que com os avanços das tecnologias de comunicação os embates no espaço virtual passaram a ter natureza estratégico-discursiva. As ações concretas de comunicação tornam-se operações táticas para se alcançar objetivos e exigem uma nova habilidade: capacidade de potencializar resultados em função de objetivos. Comunicar-se no mundo globalizado é saber se expressar para alcançar seus objetivos.

GESTÃO - A segunda verdade captada em Castells é a de que passam a existir duas competências essenciais, convergentes e complementares, indispensáveis e cada vez mais exigentes, nos contextos profissionais. Uma delas, a competência de gerar conteúdos que sirvam, simultaneamente, a três objetivos: alcançar sucesso operacional; construir e reforçar identidades; transformar informações em conhecimento, para o progresso social e cultural. Gerir estes conteúdos também torna-se fundamental a qualquer profissão.

COLABORAÇÃO - Igualmente importante é a competência de socializar eficazmente os conteúdos gerados, no espaço dos fluxos e na intemporalidade do tempo, com base nos recursos de comunicação e gestão de informação. Hoje, qualquer atividade profissional têm à disposição, para a socialização dos conteúdos gerados, além de uma amplitude de meios (com periodicidades, linguagens diferentes e complementares entre si) também, por consequência, infinitas possibilidades de inventar, articular e usar de forma combinada ações comunicacionais.

Em Castells (1999), a terceira verdade implícita é a de que, o poder de gerar e socializar conteúdos relevantes, deve estar associado à responsabilidade, moral e ética, pelo conteúdo que cominicamos.

O desenvolvimento destas habilidades e competências - capacidade de potencializar resultados em função de objetivos, gerar conteúdos e socializar eficazmente os conteúdos gerados - dentro do ensino de Arquitetura e Urbanismo tornará possível garantir o novo perfil de atuação profissional para arquitetos-urbanistas como gestor de processos projetuais.

4 Segundo Barreto (2000), "o objetivo da informação e de suas unidades gestoras é promover o desenvolvimento do indivíduo, de seu grupo e da sociedade através dos sistemas de produção do conhecimento". 


\section{A EXPERIÊNCIA PEDAGÓGICA: CONSTRUINDO PROCEDIMENTOS COLABORATIVOS PARA CONSTRUÇÃO DE MODELOS MULTIESCALAS INTEGRADOS}

A experiência didático-pedagógica em InfoAU-I, ora apresentada, vem sendo desenvolvida e melhorada desde 2012.2 (PORTO CARREIRO; RÊGO, 2014). Seu principal desafio tem sido a formulação de procedimentos para: (1) integrar diferentes ferramentas computacionais que utilizam plataformas de informação diferentes e (2) trabalhar de forma colaborativa com essas ferramentas, mesmo as que não possuem recursos para tal.

Devido à pequena carga horária da disciplina, 30 horas/aula, e ser a primeira disciplina da matéria de InfoAU do Curso, com estudantes calouros, alguns pré-requisitos tornam-se fundamentais para se atingir o objetivo da disciplina:

- Escolha de ferramentas de fácil aprendizado (desde 2012.2):

Isso justifica o emprego do programa SketchUp para realização do modelo geométrico 3D da área de estudo na disciplina de Projeto I, do Google My Maps para elaboração de mapas temáticos georreferenciados de várias disciplinas e do Google Earth para combinação dos dois modelos anteriores;

- $\quad$ Tratamento da unibase da área de estudo de Projeto I (desde 2012.2):

Como as áreas urbanas em estudo (seja no exercício-piloto, seja na área de atuação da disciplina de Projeto I) têm representação registrada em modelos 2D elaborados em editores gráficos, o domínio básico de manipulação de arquivos do tipo "dwg" se faz necessário. $\mathrm{O}$ trabalho inicial de ajuste do arquivo dwg da unibase da área é feito pelos monitores.

- $\quad$ Construção de Mapas Temáticos Manuais (desde 2013.1):

Os conteúdos tratados nas disciplinas de Métodos e Técnicas de Pesquisa em Arquitetura, Urbanismo e Paisagismo I, Estudos Sócioeconômicos e Ambientais I e Planejamento Urbano I, Conforto Ambiental I e Projeto I são sintetizados em mapas temáticos para subsidiar compreensão e análises da área de estudo, que são integrados em mapas temáticos georreferenciados;

- Construção de recursos de gestão, comunicação e colaboração para a InfoAU I (desde 2013.1):

A gestão da própria disciplina reflete as orientações repassadas aos alunos quanto ao uso de ferramentas de informações. São elas: e-mail (infoau01.cau.ufpe@gmail.com); área de armazenamento em nuvem (google drive); perfil em ambiente de interação social (grupo no Facebook) e construção de planilha eletrônica para controle de notas e frequências;

- Reavaliação da metodologia do semestre anterior (desde 2014.1):

O processo de reavaliação pedagógica vem desde 2012.1, contudo, só a partir de 2014 , utilizando-se princípios da metodologia da pesquisa-ação.

- Construção do exercício-piloto (desde 2014.2):

É importante registrar que só em 2014.2 utilizou-se um exercício-piloto para construir os procedimentos de integração e de colaboração. Este exercício foi elaborado e testado pelos monitores da disciplina em discussão com as professoras, antes do início da disciplina. Assim, permitiu-se avaliar as dificuldades e, principalmente, corrigir e ajustar etapas e passos do processo para viabilizar sua adoção na carga horária da disciplina.

Pode-se perceber que esses pré-requisitos vêm sendo construídos e melhorados, semestre a semestre, tomando-se princípios da metodologia pesquisa-ação como: (a) "interação entre pesquisador e sujeitos como forma de determinação de objetivos e condução da pesquisa" atores e parceiros interessados na resolução dos problemas; (b) tem por objetivo "resolver ou, 
pelo menos, esclarecer os problemas da situação observada" e retroalimentar o problema experiência como experimento; (c) "acompanha as decisões, as ações e toda a atividade dos atores da situação" - compreensão do processo como principal resultado (THIOLENT, 1994).

Ressalta-se, também, o importante papel que o programa de monitoria da UFPE vem desempenhando nos resultados aqui apresentados, pois é por meio dele que efetivamente se estar melhorando a experiência pedagógica de InfoAU-I. Os alunos que se tornam monitores, no semestre seguinte ao cumprimento de InfoAU-I, discutem e reavaliam o processo adotado e do qual participaram, propõem ajustes e ajudam efetivamente a melhorar o processo. Vivenciam de forma diferente o processo projetual e desenvolvem visão estratégica, habilidades e competências que corroboram para se tornarem gestores do processo projetual integrado.

Neste artigo, as duas primeiras autoras são as professoras da disciplina, enquanto os quatro últimos coautores foram alunos em 2014.1 e monitores de InfoAU-I em 2014.2. Este fluxo vem se repetindo há três semestres e com ele a evolução da disciplina. As seções a seguir descrevem as etapas dos procedimentos colaborativos para construção de modelos multiescalas integrados e contaram com a efetiva participação dos supracitados monitores na construção e descrição dos mesmos.

\subsection{Exercício-piloto: colaborando e integrando por meio de modelo simplificado}

O exercício-piloto objetivou a rápida compreensão e assimilação dos procedimentos sugeridos pela disciplina para o trabalho colaborativo de construção de modelo geométrico 3D de uma área urbana e para a integração deste modelo com os mapas temáticos georreferenciados desta área. Julga-se que, se devidamente entendido, ambos os procedimentos - de colaboração e de integração - no exercício-piloto de menor complexidade, poderão ser replicados para realização de trabalho de mesma natureza, com maior complexidade, na área de intervenção de Projeto I, no mesmo semestre, ou em qualquer outra área estudada em qualquer outra disciplina do curso, envolvendo a turma toda.

Nesse intuito, buscou-se identificar uma solução espacial integrada, contemporânea, exemplo da indissociabilidade das escalas do ato projetual (edifício/paisagem/cidade) preconizada pelo PPC2010, de fácil compreensão aos iniciantes e com a dimensão e complexidade necessárias para se constituir o exercício-piloto da disciplina.

A Unidade de Vizinhança (UV) foi conceito espacial escolhido, pois traz todos os requisitos acima descritos além de termos exemplar importante no país: a UV do Plano Piloto de Brasília, projetada por Lúcio Costa. Pensada como uma área residencial autônoma pela existência de equipamentos de uso coletivo, de bens e serviços, e áreas de lazer alocados nos limites da área residencial, tendo a escola como elemento estruturador do conjunto. Focada na recuperação da vida social ou relações de vizinhança que foram se perdendo com as transformações urbanas.

Adotou-se, assim, uma Superquadra (SQ) da cidade de Brasília como objeto de modelagem $3 \mathrm{D}$ individual, para posterior modelagem 3D colaborativa da UV, com junção planejada de quatro SQs.

Para tanto, iniciou-se o processo de modelagem pela apresentação dos princípios do Plano Piloto de Brasília (LEITÃO, 2009), entre eles os de SQ e de UV (ver Figura 01, 02 e 03). 
Figura 01 - Conceitos do Plano Piloto de Brasília de Lúcio Costa.

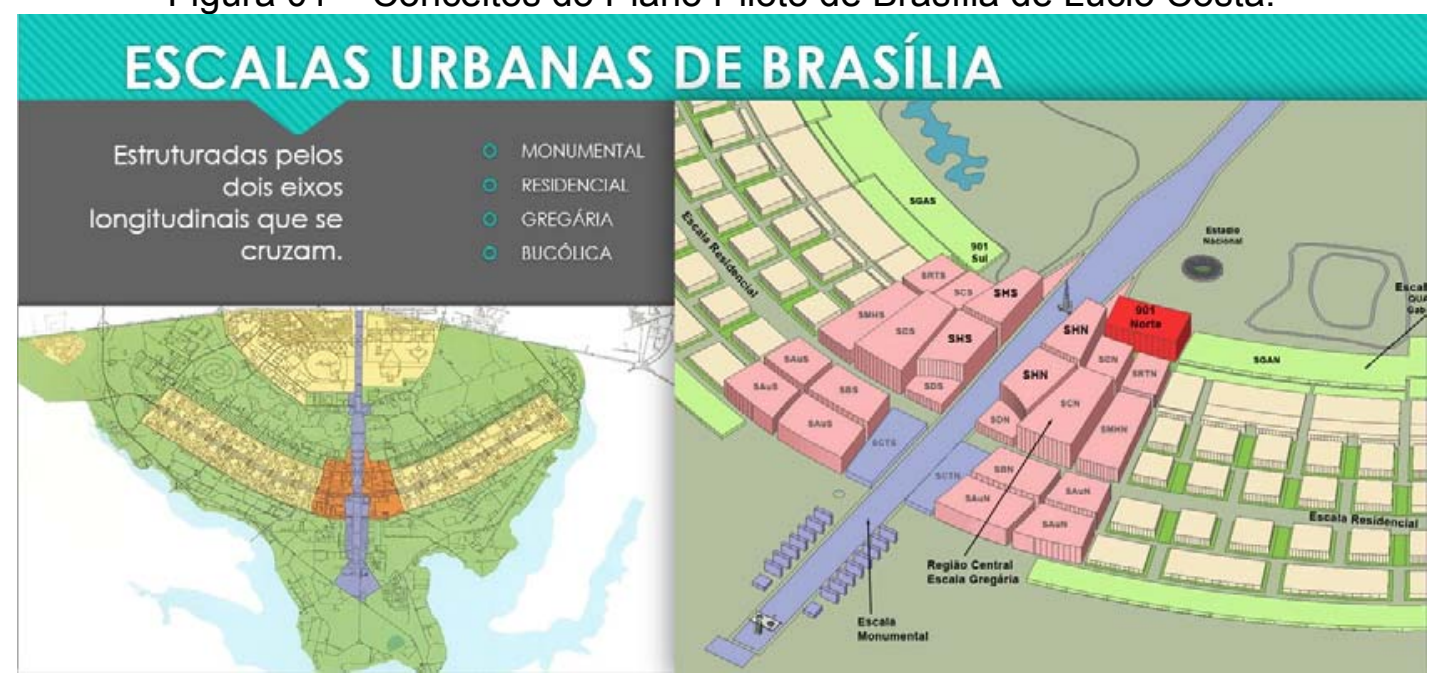

Fonte: Monitores de InfoAU-I, 2014.2

Figura 02 - Princípios modernistas de Unidades de Vizinhança.

\section{UNIDADE DE VIZINHANÇA propostas}
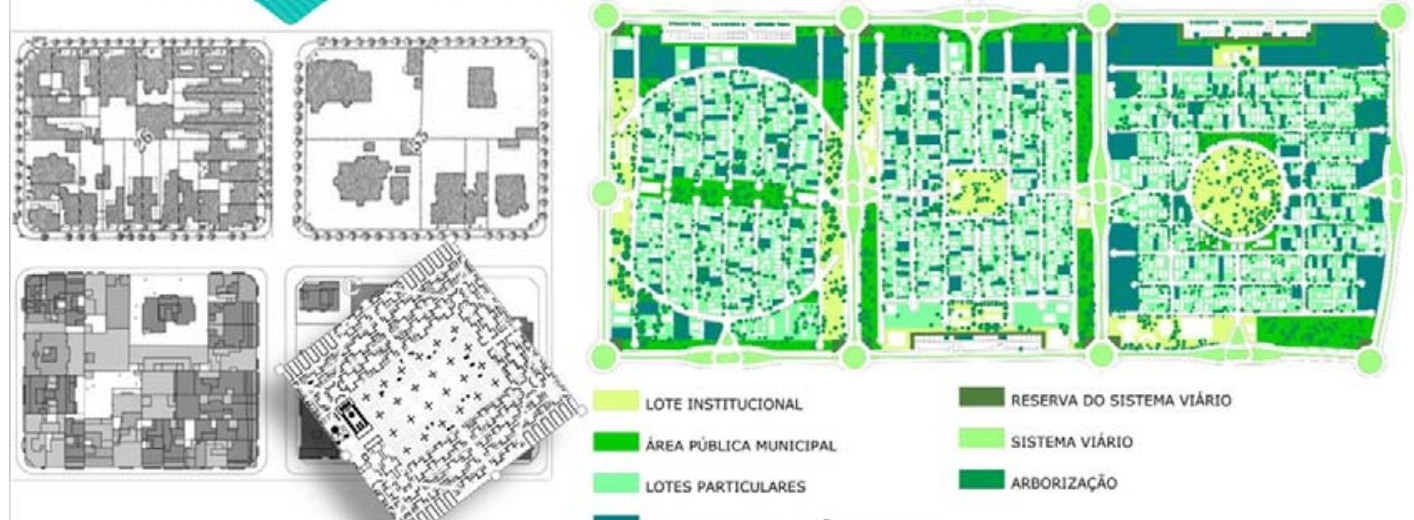

Fonte: Monitores de InfoAU-I, 2014.2

Figura 03 - Propostas de Superquadras e Unidades de Vizinhança em Brasília.

\section{UNIDADE DE VIZINHANÇA_LÚcio Costa}
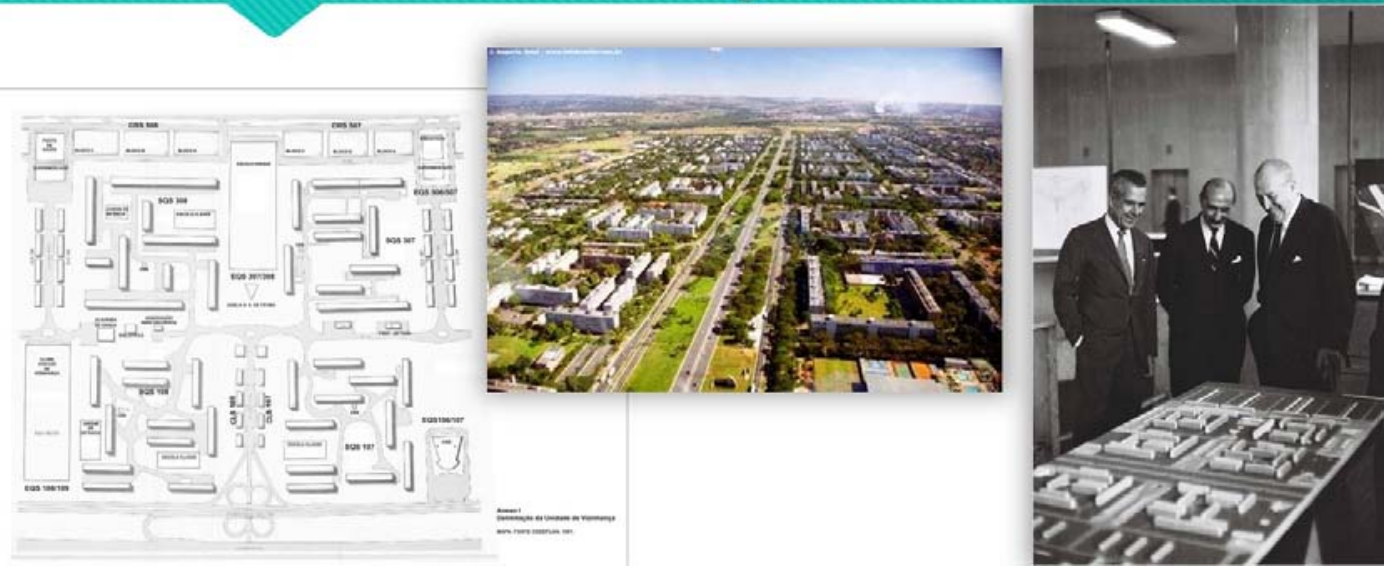
Em seguida, passou-se às seguintes etapas:

ETAPA 1: Apresentação e explicação do procedimento de preparação da unibase da área estudada

Como dito anteriormente, há um trabalho precedente feito pelos monitores que se iniciou pela pesquisa e acesso à unibase em formato "dwg" da cidade de Brasília. Esse procedimento foi otimizado pelo fácil acesso e organização do site do Governo do Distrito Federal, cuja página da Secretaria de Estado de Gestão do Território e Habitação reúne em "informações urbanas", diversos mapas, entre eles a denominada "Planta Urbana de Brasília" (http://www.sedhab.df.gov.br/desenvolvimento-urbano/gestao-da-informacao-

urbanas/mapas.html). A unibase em formato $\mathrm{dwg}$ possui estrutura bem formulada e clara das camadas de informações (layers), contribuindo para facilitar o tratamento do arquivo.

Procedeu-se o seguinte tratamento da unibase de Brasília em formato dwg, de modo a permanecer com as informações consideradas necessárias ao propósito de modelagem geométrica 3D. Ou seja:

a. Recorte da unibase de Brasília e transferência de toda a geometria para a camada 0 (zero), deixando apenas a UV de interesse;

b. Exclusão de layers com informações dispensáveis à modelagem 3D;

c. Verificação da situação topográfica do terreno, com nivelamento para cota 0 (zero) de toda a geometria do desenho;

d. Rotação em $38^{\circ}$ da representação desejada no sentido horário, a fim de ajustar para ortogonalidade mais próxima aos eixos x e y (Figura 04);

$\mathrm{Na}$ apresentação e explicação, aos calouros, do procedimento de preparação da unibase da área estudada, mostraram-se os passos acima detalhados para posterior uso na modelagem geométrica 3D, de modo que os estudantes compreendessem a necessidade desse tratamento e consequentes dificuldades e problemas que podem surgir no caso de não realização da mesma.

Figura 04 - Ajuste do unibase da unidade de vizinhança do exercício-piloto

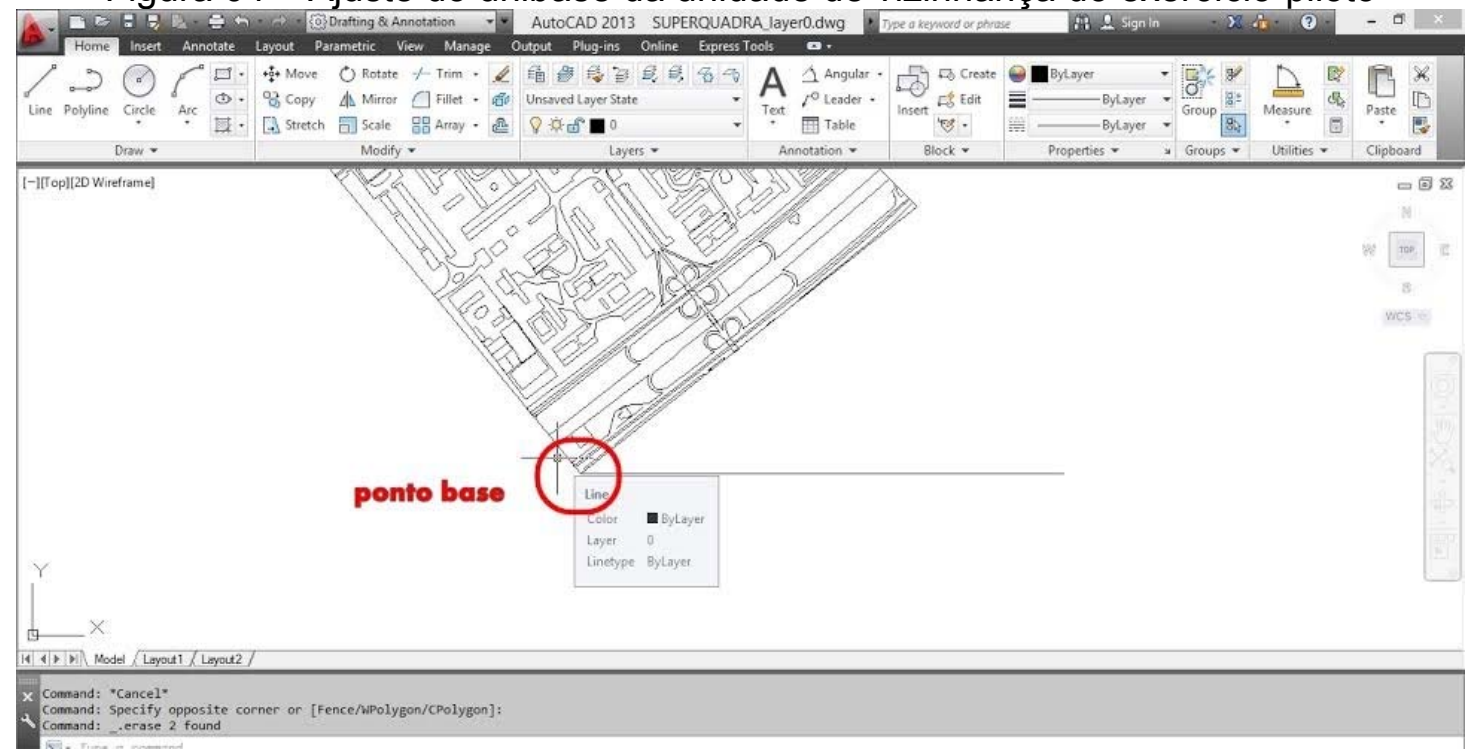




\section{ETAPA 2: Modelagem geométrica 3D das superquadras e unidade de vizinhança}

De posse da representação $2 \mathrm{D}$ da área a ser modelada, essa fase destinou-se à construção no modelo geométrico 3D, por meio de trabalho colaborativo, onde cada estudante do grupo ficou responsável por uma das 4 (quatro) SQs da unidade de vizinhança. Uma vez concluída as modelagens individuais, a UV resultaria da junção das SQs. Para êxito da modelagem final, os estudantes foram alertados a seguir, rigorosamente, procedimentos de organização da informação e de emprego de determinados recursos do programa computacional utilizado (SketchUp). Essa etapa constou dos seguintes passos:

a. Importação do arquivo dwg para o programa SketchUp;

b. Criação de layers de acordo com os usos das edificações das SQs, definindos por cor (Figura 05);

c. Construção de grupos para determinar unidades importantes no modelo;

d. Construção de componentes para unidades que iriam ser reproduzidas no modelo;

e. Divisão da UV entre os membros do grupo (Figura 06);

Figura 05 - Organização das camadas de acordo com os usos, definidos por cor.

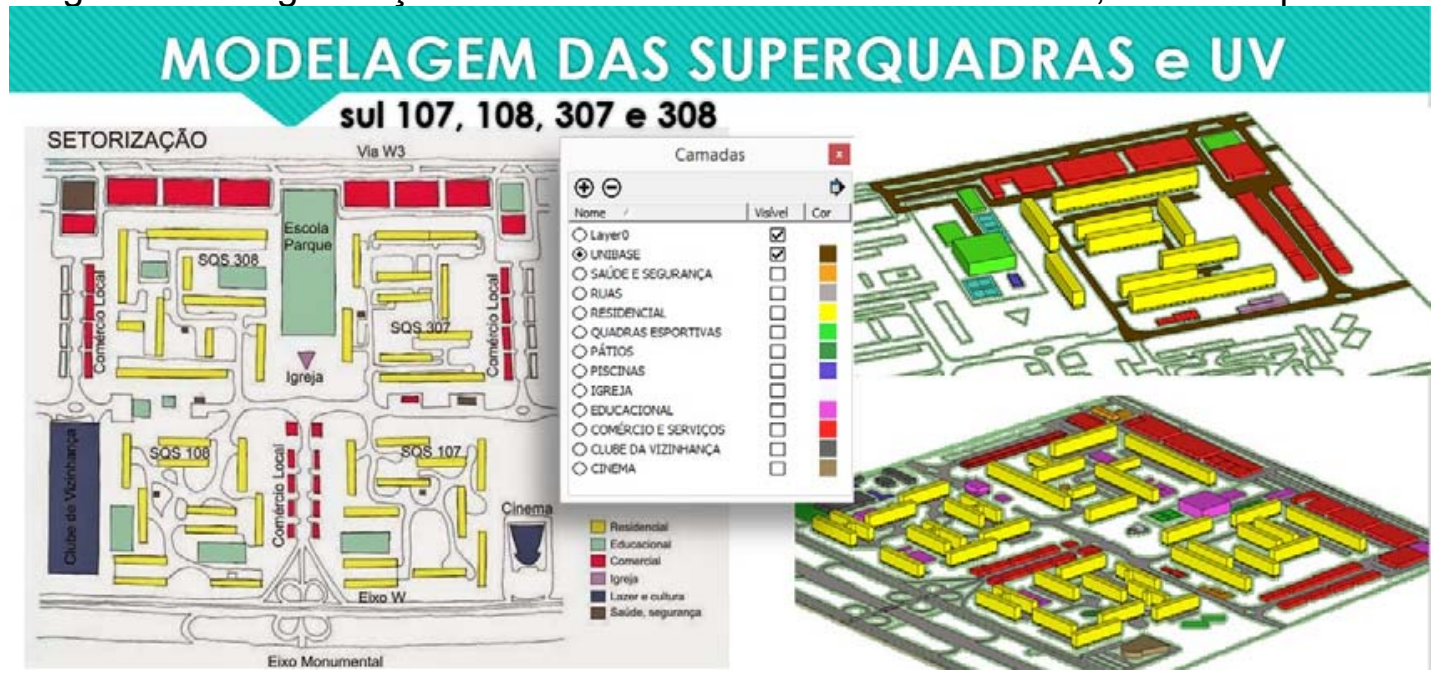

Fonte: Monitores de InfoAU-I, 2014.2

f. Modelagem das edificações

- Desenho das superfícies nas respectivas camadas por tipo de uso;

- Extrusão das poligonais para criação da volumetria, de acordo com a quantidade de pavimentos, adotando-se $3 \mathrm{~m}$ de altura para cada pavimento. Para identificação do número de pavimentos, utilizou-se o Google Maps e o Google Street View;

- Uso de modulação de pilares para as edificações em pilotis, de modo a otimizar a execução da modelagem. Para adequar a modelagem ao tempo disponível na disciplina, adotou-se a forma retangular para todos os pilares, substituindo os que possuem forma em " $\mathrm{V}$ " na edificação real. Esse ajuste não comprometeu a percepção volumétrica.

- Modelagem de detalhes como piscinas e quadras de esportes;

- Modelagem de ruas de toda a UV por um único membro da equipe (Figura 07);

- Exclusão da representação importada do arquivo dwg de todas as modelagens de SQ, mantendo-a somente no arquivo com a modelagem das ruas; 
- Junção dos modelos das SQs e das ruas tomando como referência a origem do sistema $\mathrm{x}, \mathrm{y}(0,0)$ (Figura 08);

- Geolocalização do modelo reposicionando-o na configuração original do mapa, a fim de compatibilizar com o mapa do local (Figura 09).

Figura 06 - Divisão das SQs

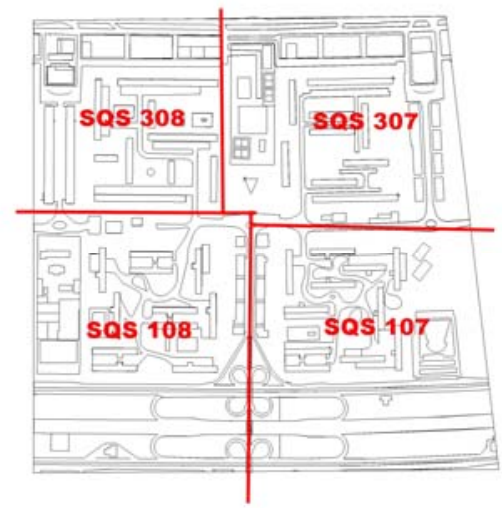

Figura 07 - Modelagem das ruas

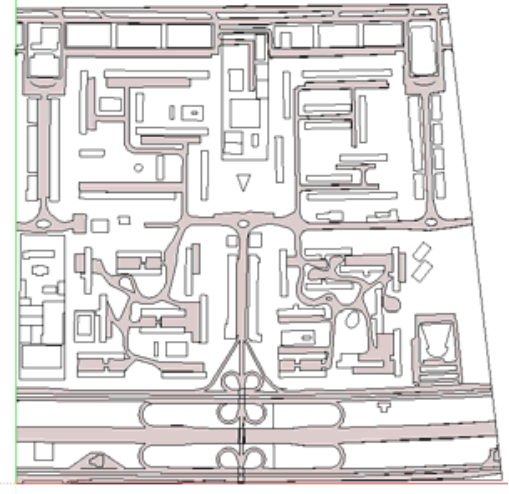

Fonte: Monitores de InfoAU-I, 2014.2

Figura 08 - Modelo da UV resultante da junção das SQs

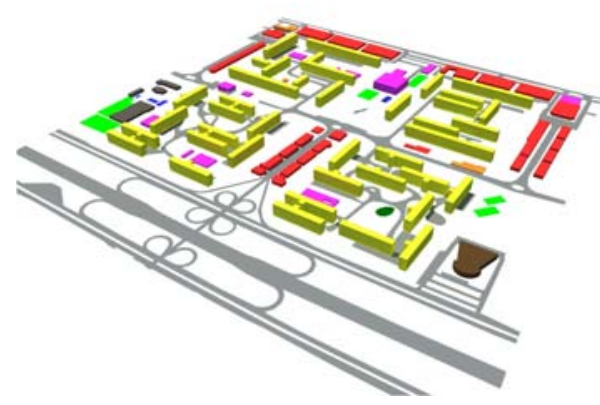

Figura 09 - Geolocalização do modelo da UV

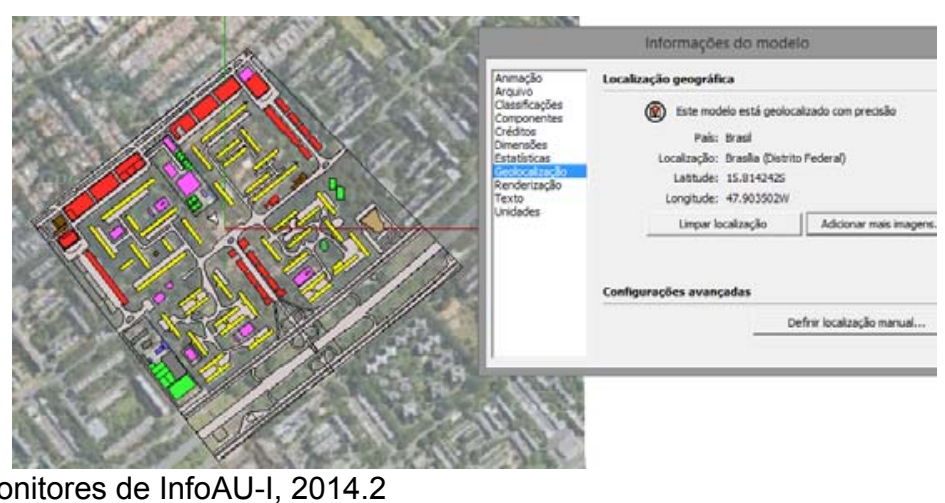

ETAPA 3: Inserção do modelo da UV no Google Earth

Com o modelo completo e georreferenciado da UV, a última etapa do processo foi a sua exportação para a plataforma do Google Earth, em formato de arquivo "kml". Para tanto, excluiu-se a imagem do mapa utilizada para ajudar no posicionamento georreferenciado do modelo. No Google Earth a visualização de satélite da área se deu com a própria base presente no programa.

De modo a manter a mesma estrutura e organização das camadas de informação do SketchUp, por tipo de uso das edificações, exportou-se separadamente cada uma. 
Figura 10 - Inserção do modelo da UV no Google Earth

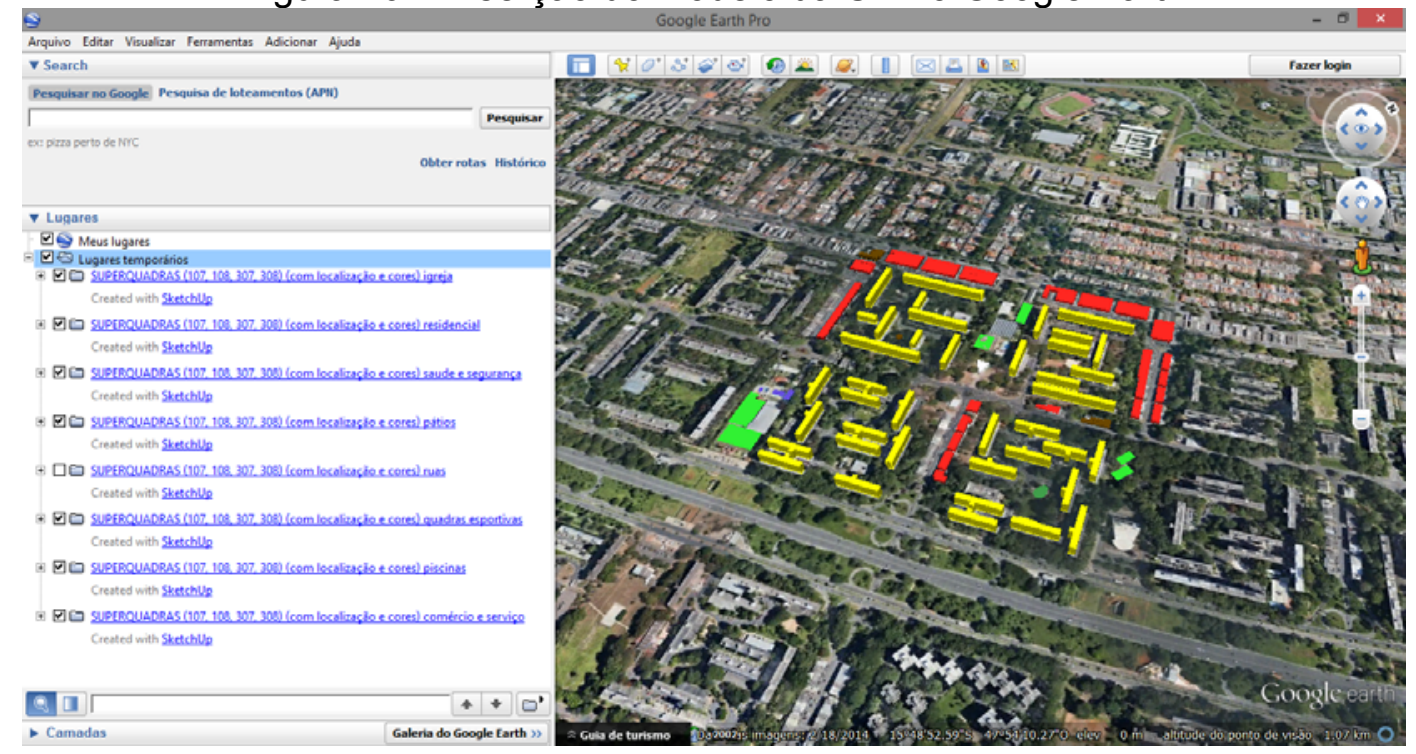

Fonte: Monitores de InfoAU-I, 2014.2

É importante registrar que todo o procedimento foi criado pelos monitores da disciplina em discussão com as professoras, antes de a disciplina iniciar. Esse trabalho permitiu avaliar as dificuldades e, principalmente, corrigir e ajustar etapas e passos do processo para viabilizar sua adoção na carga horária da disciplina, como já assinalado.

Por ter acontecido um feedback entre os monitores e os professores sobre os problemas encontrados na construção da modelagem da área de estudo do período anterior à monitoria, foi procurado não repetir os erros com a modelagem das SQs. Por isso foi preciso a organização das tarefas com base na metodologia já citada, tentando racionalizar as soluções dos possíveis problemas que seriam encontrados durante a execução do modelo. Contudo, a maior dificuldade encontrada ao modelar foi identificar a quantidade de pavimentos dos edifícios localizados nas ruas em que não se consegue visualizar pelo Google Street View. Foi necessário estimar, comparando com os edifícios identificáveis no entorno, visto que, no caso de Brasília, os residenciais são de mesmo gabarito. No mais, não foram encontradas dificuldades.

Os procedimentos listados acima, aprendidos com o exercício-piloto, foram replicados com sucesso pela turma de 2014.1 na construção colaborativa do modelo 3D da área de intervenção de Projeto I, no Bairro de Beberibe em Recife (Figura 11). 


\section{TIC2015}

Figura 11 - Etapas da construção do Modelo Multiescalas Integrado do Bairro de Beberibe, Recife-PE
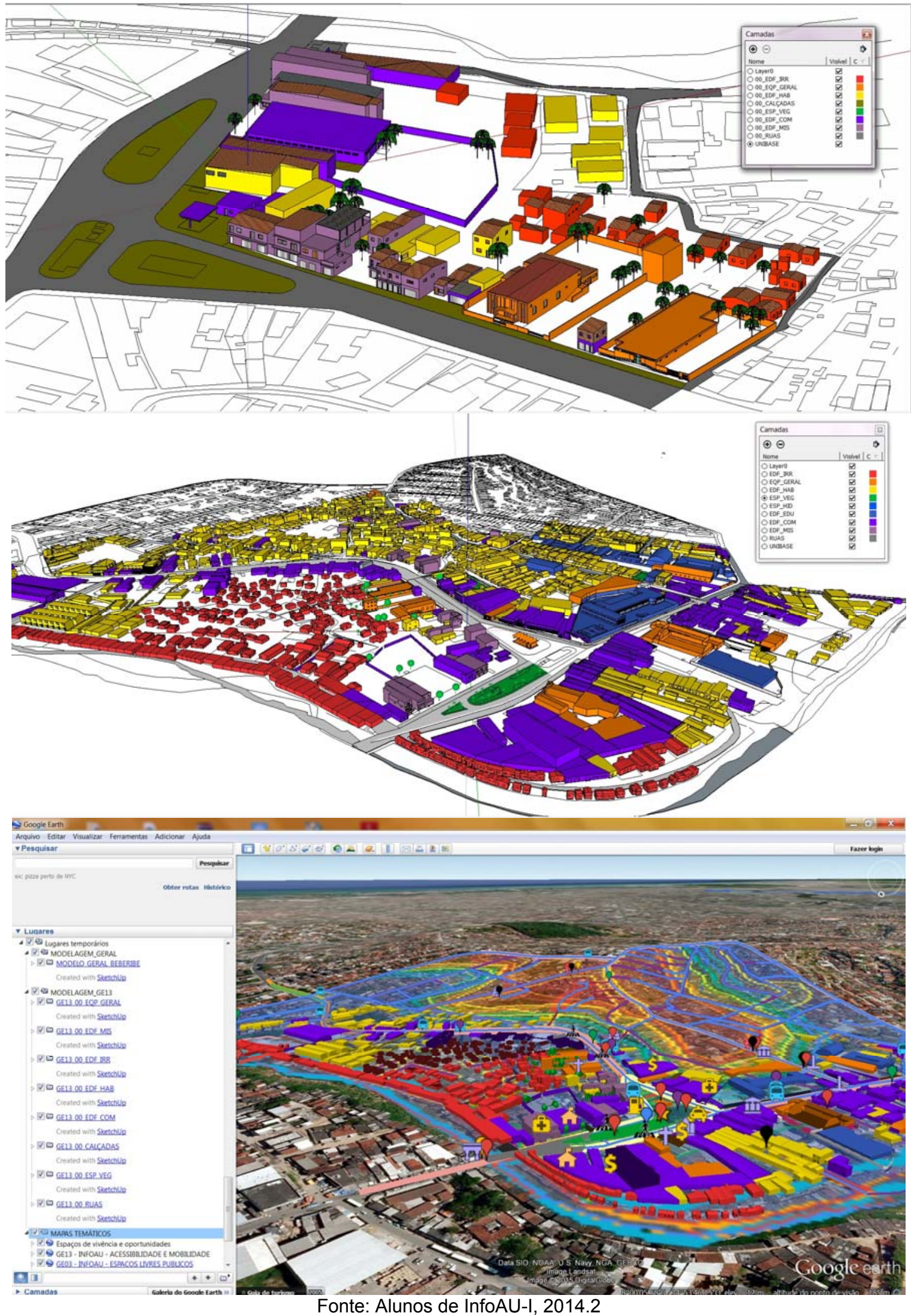


\section{CONCLUSÕES}

$\mathrm{O}$ artigo apresentou a experiência didático-pedagógica realizada na disciplina InfoAU-I do Curso de Arquitetura e Urbanismo/UFPE, cujo foco foi a construção colaborativa de modelos multiescalas integrados.

Tendo-se como um dos princípios didático-pedagógico do novo Projeto Pedagógico do Curso/PPC2010, a indissociabilidade do ato projetual nas escalas da paisagem, da cidade e do edifício, demonstrou-se como a construção de modelos multiescalas integrados podem corroborar na compreensão e projetação de soluções espaciais integradas.

Atribuindo-se, ainda, o perfil de gestor de processos projetuais ao arquiteto-urbanista, também preconizado pelo PPC2010, utilizou-se e construiu-se procedimentos para uso consciente dos recursos das tecnologias de Gestão, Colaboração e Comunicação não só para melhorar o gerenciamento das informações dos processos projetuais, mas também para a gestão da própria experiência relatada.

Como principal resultado, alcançou-se por parte de todos os envolvidos na experiência, a conscientização de que o processo de projetação necessita não só de recursos conceituais e instrumentais, mas, também, de procedimentos metodológicos e gerenciais para ser devidamente realizado. Os resultados ainda indicam que a experiência tem sido satisfatória, em se tratando de estudantes calouros, que passam a trabalhar com a indissociabilidade do ato projetual em modelos multiescalas, reforçando o PPC2010. Contudo, ainda se faz necessário testar a integração de alguns aspectos das ferramentas adotadas, melhorar os procedimentos de colaboração nas ferramentas que não dão suporte a tal abordagem, assim como melhorar os procedimentos de integração para evitar problema na junção dos modelos.

A matéria de Informática aplicada à Arquitetura e Urbanismo do CAU/UFPE vem construindo procedimentos para integrar [1] recursos das Tecnologias de Gestão, Colaboração e Comunicação de informações, [2] um ou mais tipos de sistemas de informação de plataformas computacionais específicas: geométrica, geográfica, topológica, semântica, etc e [3] fazendo experimentações pedagógicas para testar as duas ações anteriores. Nas três disciplinas obrigatórias da matéria têm-se procurado desenvolver conteúdos, procedimentos e dinâmicas que potencializem os princípios pedagógicos do CAU/UFPE. Compreende-se que os resultados obtidos são suficientes e relevantes para embasar desdobramentos na matéria de InfoAU, nas outras matérias e no curso como um todo, dando suporte à busca constante de métodos, procedimentos e instrumentos que apoiem o processo do ensino projetual integrado, reflexivo e contextualizado com as demandas sociais. Pois, integrar conteúdos programáticos é, acima de tudo, integrar o pensamento pedagógico e as práticas de ensino projetual no CAU/UFPE.

\section{AGRADECIMENTOS}

Aos estudantes da disciplina no período de 2012.2 a 2015.1 por aceitarem o desafio proposto e possibilitarem aprofudar reflexões e encaminhamentos sobre novas abordagens didáticopedagógicas.

\section{REFERÊNCIAS}

AMORIM, L., LEITE, M. J., GONÇAlVES, G. M., PORTO CARREIRO, P. Projeto Pedagógico do Curso de Arquitetura e Urbanismo da UFPE - Diretrizes da Reforma Curricular 2010, Recife: CCEPE-UFPE, julho de 2010.

BARRETO, A. A. Agregados de informação: memórias, esquecimento e estoques de informação. DataGramaZero: Revista de Ciência da Informação, Rio de Janeiro, v. 1, n. 3, jun. 2000. Disponível: <http://dgz.org. br/jun00/Art_01.htm>. Acesso em: 27 abr. 2015.

CASTELLS, M. A era da informação: economia, sociedade e cultura. v. 1, 2 e 3. São Paulo: Paz e terra, 1999. 
LEITÃO, F. (org.). Brasília 1960-2010: passado, presente e futuro. Brasília: Secretaria de Estado de Desenvolvimento Urbano e Meio Ambiente, 2009. 272p

PORTO CARREIRO, P.; RÊGO, R. M. Mapas Mentais e Ferramentas Computacionais na Gestão da Informação do Processo de Ensino Projetual da Arquitetura, Urbanismo e Paisagismo. In: Anais 17 SiGRADi 2013 - XVII Congreso de la Sociedad Iberoamericana de Gráfica Digital, Vol. 1, p.?-?, Valparaíso, Chile, 2013.

Novas práticas pedagógicas da matéria de Informática aplicada à Arquitetura, Urbanismo e Paisagismo: Experimentações dentro do Novo Currículo do Curso de Arquitetura e Urbanismo/UFPE. XXXIII ENSEA/ XXXVI COSU: O Ensino de Arquitetura e Urbanismo: Teoria e Prática. ABEA, 39, p.224-242. 2014.

RIBEIRO, D. O processo civilizatório - etapas da evolução sociocultural. São Paulo: Companhia das Letras, 2001.

THIOLENT, M. Metodologia da pesquisa-ação. São Paulo: Cortez,1994. 